\title{
Does COVID19 Infect the Brain? If So, Smokers Might Be at a Higher Risk
}

\author{
Nadine Kabbani and James L. Olds \\ School of Systems Biology, George Mason University, Fairfax, Virginia (N.K.) and Schar School of Policy and Government, \\ George Mason University, Arlington, Virginia (J.L.O.)
}

Received March 20, 2020; accepted March 27, 2020

\section{ABSTRACT}

COVID19 is a devastating global pandemic with epicenters in China, Italy, Spain, and now the United States. While the majority of infected cases appear mild, in some cases, individuals present serious cardiorespiratory complications with possible long-term lung damage. Infected individuals report a range of symptoms from headaches to shortness of breath to taste and smell loss. To that end, less is known about how the virus may impact different organ systems. The SARS-CoV2 virus, which is responsible for COVID19, is highly similar to SARS-CoV. Both viruses have evolved an ability to enter host cells through direct interaction with the angiotensin converting enzyme (ACE) 2 protein at the surface of many cells. Published findings indicate that SARS-CoV can enter the human nervous system with evidence from both postmortem brains and detection in cerebrospinal fluid of infected individuals. Here, we consider the ability of SARS-CoV2 to enter and infect the human nervous system based on the strong expression of the ACE2 target throughout the brain. Moreover, we predict that nicotine exposure through various kinds of smoking (cigarettes, electronic cigarettes, or vape) can increase the risk for COVID19 neuroinfection based on known functional interactions between the nicotinic receptor and ACE2. We advocate for higher surveillance and analysis of neurocomplications in infected cases.

\section{SIGNIFICANCE STATEMENT}

The COVID19 epidemic has spurred a global public health crisis. While many of the cases requiring hospitalization and intensive medical care center on cardiorespiratory treatment, a growing number of cases present neurological symptoms. Viral entry into the brain now appears a strong possibility with deleterious consequences and an urgent need for addressing.
COVID19 belongs to a family of coronaviruses $(\mathrm{CoV})$ that have evolved in various species (Lam et al., 2016). Human-infecting CoV such as SARS and COVID19 have acquired ability to bind the angiotensin converting enzyme (ACE) 2 on epithelial cells as a primary mechanism of entry into the host (Qi et al., 2020). Critical cases of COVID19 infection commonly manifest as cardiopulmonary symptoms and in severe cases advance into organ failure and sepsis as a result of a "cytokine storm" over activation of the immune system (Guan et al., 2020). The case fatality rate is still unclear but is likely anywhere from $0.4 \%$ to $4 \%$ and depends critically on the ability of public health systems to provide intensive supportive care. Recently, we have raised the question of whether nicotine exposure through cigarette smoke (and other formulas) is a comorbidity factor in COVID19 infection and clinical outcome (Olds and Kabbani, 2020). Functional interactions between nicotine exposure and ACE2 expression in lungs and other organ systems such as heart and kidneys as well as nicotine and other components of

https://doi.org/10.1124/molpharm.120.000014. the renin angiotensin system (RAS) suggest that smoking can promote COVID19 cellular entry through nicotinic acetylcholine receptor ( $\mathrm{nAChR}$ ) signaling. Notably, nAChRs are known to be on many of the same cells that express ACE2 in the lungs, kidneys, circulation, and brain (Changeux, 2010; Tolu et al., 2013; Nordman et al., 2014). Thus, smoking can impact COVID19 pathophysiology and clinical outcome in several organ systems.

Differential host factors such as age, health, simultaneous infection, and genetics are known determinants of susceptibility to a viral infection. Smoking is a strong factor in predicting an individual's likelihood of developing and managing a viral infection and especially a respiratory infection (Razani-Boroujerdi et al., 2004; Eddleston et al., 2011). Here, we raise the question of nicotine-associated comorbidity to COVID19 in the context of the brain based on published evidence that the viral target receptor ACE2 is expressed in the brain and functionally interacts with nAChRs (Ferrari et al., 2007; Oakes et al., 2018). We consider if neural cells, such as epithelial cells, are more vulnerable to infection in 
smokers because nicotine stimulation of the nAChR can increase ACE2 expression within them (Olds and Kabbani, 2020). This issue is critical because evidence shows that mRNA from the closely related SARS virus, which also binds ACE2 as a mechanism of cell entry, was detected in brain and cerebrospinal fluid of infected individuals (Zhang et al., 2003; Chong et al., 2004; Inoue et al., 2007). Moreover, SARS ability to enter neurons is established in experimental systems using recombinant human ACE2 as the point of entry (Netland et al., 2008; Kaparianos and Argyropoulou, 2011).

Now is the time to ask if infection with COVID19 can result in long-term neural damage in both symptomatic and asymptomatic individuals and if chronic nicotine exposure through smoking habits and addiction increases risk of developing COVID19-associated neuropathology through interactions between $\mathrm{nAChRs}$ and ACE2 in neurons and glia.

Functional interaction between nicotine and components of the RAS (such as ACE2) are well established in several organ systems including the lungs where smoking is found to impact cardiopulmonary health (Ferrari et al., 2008; Virdis et al., 2010; Fuchs et al., 2018). Similar RAS components also exist in the human brain, and nicotine exposure is documented to modulate RAS activity in areas such as the hypothalamus and brain stem, leading to changes in endocrine release as well as hypertension, respectively (Ferrari et al., 2007; Oakes et al., 2018). In the brain, as elsewhere, ACE2 metabolizes angiotensin II to produce angiotensin 1-7, and this process occurs in neurons as well as astrocytes (Hung et al., 2016). ACE2 signaling is widely thought to oppose oxidative stress and neuroinflammation and disruption in ACE function, and balance can drive neurodegeneration of dopaminergic neurons (Labandeira-García et al., 2014). ACE activity may also contribute to cortical cholinergic pathways and participate in the progression of Alzheimer disease (Kehoe et al., 2009). Figure 1 depicts areas of notable ACE2 mRNA expression such as the cortex, striatum, hypothalamus, and brainstem within the adult human brain as based on microarray data from the Allen Brain Atlas (Jones et al., 2009). These regions, which are known to also express various types of nAChRs (Dani and Bertrand, 2007), are putative sites for primary infection with COVID19 in the human brain. Interactions between $\mathrm{nAChRs}$ and ACE2 have been studied in several of these regions including the ventrolateral medulla (Deng et al., 2019), and smoking may lead to enhanced viral infection through the ability of nicotine to upregulate $\mathrm{nAChRs}$ in regions such as the lungs (Plummer et al., 2005; Thorgeirsson et al., 2008; Changeux, 2010). In this case, upregulation of nAChRs in either/both neurons and astrocytes could promote greater viral entry and replication through augmented ACE2 expression in the cell (Fig. 2A).

In conclusion, we suggest that were COVID19 to breach the blood brain barrier (as evidence suggests for SARS) during the course of ongoing infection, interactions with ACE2 in multiple brain regions would present the virus the opportunity to infect the brain of COVID19 patients. Disruptions to the blood brain barrier may especially be more probable in severe cases of infection and associated with strong immunologic responses such as the cytokine storm pathologies as well as adenovirus coinfection (Channappanavar and Perlman, 2017). In one scenario, neural cells could serve as latent reservoirs for the virus but also produce debilitating neurologic symptoms with adverse affects on vascular homeostasis, adaptive immunologic responses, and cognitive function (Fig. 2). Supporting our concern, a recent report suggests that over $30 \%$ of 814 retrospectively studied COVID19 patients showed neurologic symptoms (Mao et al., 2020). The above supports the notion that COVID19 may pose a risk for brain infections and suggests that smokers as well as immune compromised individuals are at higher risk for neurologic complications. The evidence calls for careful studies on postmortem COVID19 patients' brains and for continued surveillance for signatures of the virus beyond lung, cardiac, and renal tissue.
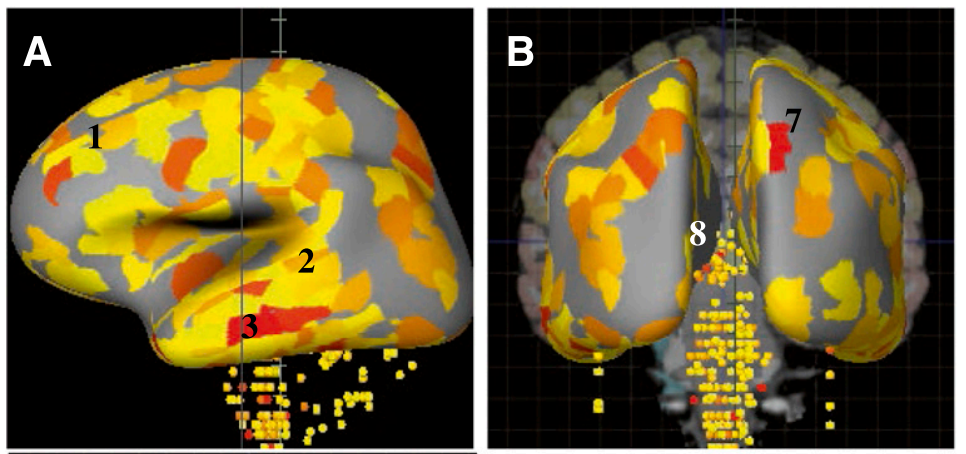

1. Motor Cortex

2. Auditory Cortex

3. Temporal Gyrus

4. Hippocampus

5. Caudate Nucleus

6. Hypothalumus

7. Somatosensory Cortex

8. Lateral Ventricle

9. Medula

10. Brainstem
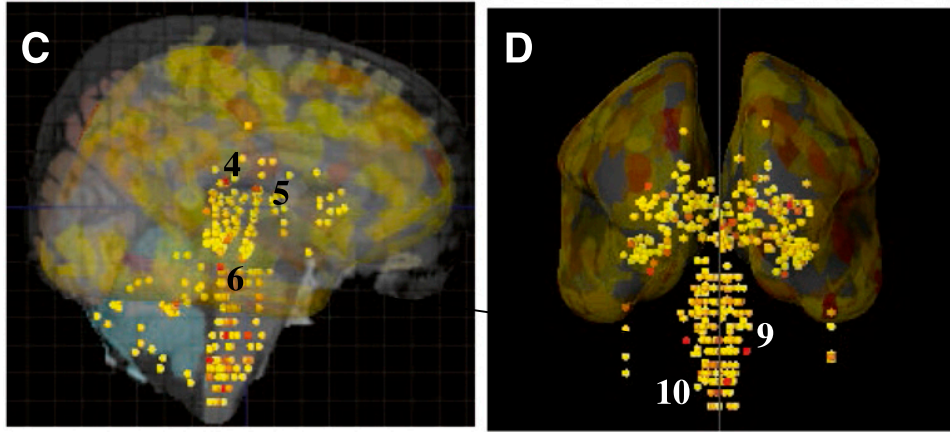

Fig. 1. Images taken from the Allen Human Brain Atlas (http://www.proteinatlas. org) show the expression of the $\mathrm{CoV}$ target ACE2 in the adult human brain. ACE2 mRNA distribution is widespread throughout the brain with notable strong expression in some of the indicated regions. Images shown are from a search for the human adult ACE2 gene (http://human. brain-map.org/microarray/search/show? exact_match=true\&search_term=ACE2\& search_type $=$ gene\&donors $=10021,15496$, $14380,12876,9861,15697)$. Areas of possible COVID19 infection include the cortex, striatum, hypothalamus, medulla, and brainstem nuclei important for hearing and balance. A. Sagittal plane, left hemisphere; B. Coronal plane, caudal; C \& D. Subcortical and brainstem expression of ACE2 in the sagittal and coronal planes, respectively. 


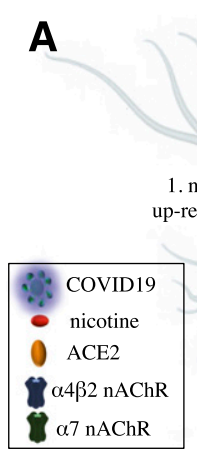

astrocyte

B

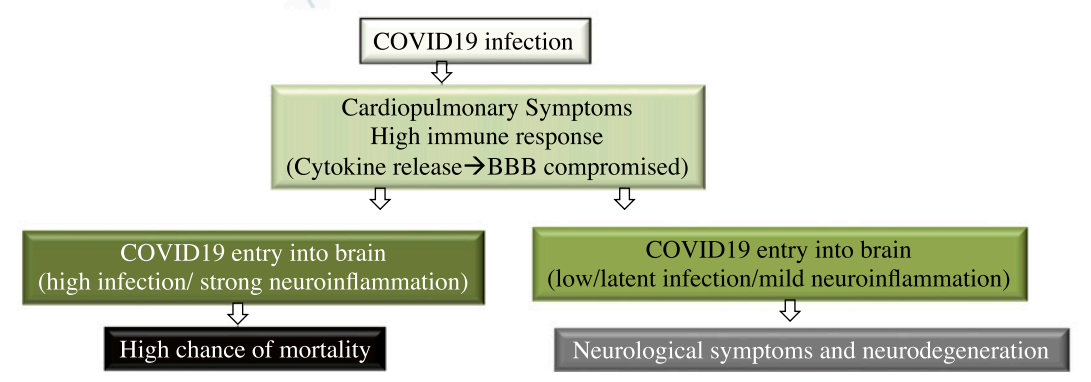

neuron

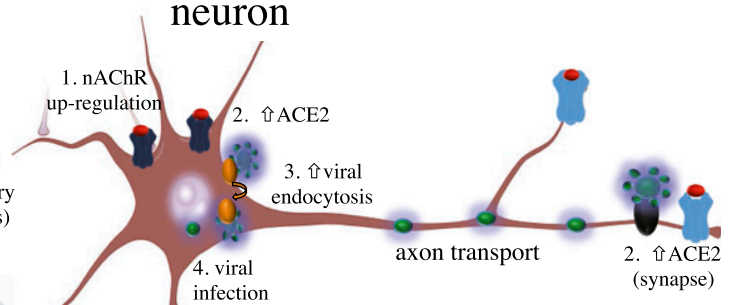

oxidative stress

neurodegeneration $\checkmark$ neurotrophin production

$\checkmark$ cytokine release

viral spreading

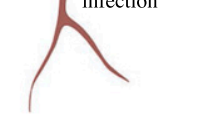

(synapse)

Fig. 2. Mechanisms of ACE2 entry and COVID19 infection in neural cells. (A) A role for nicotine-associated upregulation of nAChRs in ACE2 expressing astrocytes and neurons. Based on published findings, upregulation of nAChRs can also increase ACE2 cell surface expression, thereby enhancing viral entry and infection. (B) A putative clinical timeline for progression of COVID19 into the brain.
Future studies should also include a postmortem analysis of brains from smokers versus nonsmokers.

\section{Authorship Contributions}

Wrote or contributed to the writing of the manuscript: Kabbani, Olds.

\section{References}

Changeux J-P (2010) Nicotine addiction and nicotinic receptors: lessons from genetically modified mice. Nat Rev Neurosci 11:389-401.

Channappanavar R and Perlman S (2017) Pathogenic human coronavirus infections: causes and consequences of cytokine storm and immunopathology. Semin Immunopathol 39:529-539.

Chong PY, Chui P, Ling AE, Franks TJ, Tai DYH, Leo YS, Kaw GJL, Wansaicheong G, Chan KP, Ean Oon LL, et al. (2004) Analysis of deaths during the severe acute respiratory syndrome (SARS) epidemic in Singapore: challenges in determining a SARS diagnosis. Arch Pathol Lab Med 128:195-204.

Dani JA and Bertrand D (2007) Nicotinic acetylcholine receptors and nicotinic cholinergic mechanisms of the central nervous system. Annu Rev Pharmacol Toxicol 47: $699-729$.

Deng Y, Tan X, Li ML, Wang WZ, and Wang YK (2019) Angiotensin-converting enzyme 2 in the rostral ventrolateral medulla regulates cholinergic signaling and cardiovascular and sympathetic responses in hypertensive rats. Neurosci Bull 35:67-78.

Eddleston J, Lee RU, Doerner AM, Herschbach J, and Zuraw BL (2011) Cigarette smoke decreases innate responses of epithelial cells to rhinovirus infection. Am $J$ Respir Cell Mol Biol 44:118-126.

Ferrari MFR, Raizada MK, and Fior-Chadi DR (2007) Nicotine modulates the reninangiotensin system of cultured neurons and glial cells from cardiovascular brain areas of Wistar Kyoto and spontaneously hypertensive rats. J Mol Neurosci 33: 284-293.

Ferrari MFR, Raizada MK, and Fior-Chadi DR (2008) Differential regulation of the renin-angiotensin system by nicotine in WKY and SHR glia. J Mol Neurosci 35 151-160.

Fuchs RM, Oakes J, Basting T, Lobell T, Gilpin N, Gardner J, Yue X, and Lazartigues $\mathrm{E}$ (2018) Association of chronic nicotine inhalation with hypertension in mice. FASEB J 32 (Suppl 1):Abstract 918.7.

Guan W, Liang W, Zhao Y, Liang H, Chen Z-s, Li Y, Liu X, Chen R, Tang C, Wang T, et al. (2020) Comorbidity and its impact on 1,590 patients with COVID-19 in China: a nationwide analysis. medRxiv DOI: 10.1101/2020.02.25.20027664.

Hung YH, Hsieh WY, Hsieh JS, Liu FC, Tsai CH, Lu LC, Huang CY, Wu CL, and Lin CS (2016) Alternative roles of STAT3 and MAPK signaling pathways in the MMPs activation and progression of lung injury induced by cigarette smoke exposure in ACE2 knockout mice. Int J Biol Sci 12:454-465.

Inoue Y, Tanaka N, Tanaka Y, Inoue S, Morita K, Zhuang M, Hattori T, and Sugamura $\mathrm{K}$ (2007) Clathrin-dependent entry of severe acute respiratory syndrome coronavirus into target cells expressing ACE2 with the cytoplasmic tail deleted. J Virol 81: 8722-8729.

Jones AR, Overly CC, and Sunkin SM (2009) The allen brain atlas: 5 years and beyond. Nat Rev Neurosci 10:821-828.
Kaparianos A and Argyropoulou E (2011) Local renin-angiotensin II systems, angiotensin-converting enzyme and its homologue ACE2: their potential role in the pathogenesis of chronic obstructive pulmonary diseases, pulmonary hypertension and acute respiratory distress syndrome. Curr Med Chem 18:3506-3515.

Kehoe PG, Miners S, and Love S (2009) Angiotensins in Alzheimer's disease - friend or foe? Trends Neurosci 32:619-628.

Labandeira-García JL, Garrido-Gil P, Rodriguez-Pallares J, Valenzuela R, Borrajo A, and Rodríguez-Perez AI (2014) Brain renin-angiotensin system and dopaminergic cell vulnerability. Front Neuroanat 8:67.

Lam TT, Zhu H, Guan Y, and Holmes EC (2016) Genomic analysis of the emergence, evolution, and spread of human respiratory RNA viruses. Annu Rev Genomics Hum Genet 17:193-218.

Mao R, Liang J, Shen J, Ghosh S, Zhu LR, Yang H, Wu KC, and Chen M-H; Chinese Society of IBD, Chinese Elite IBD Union; Chinese IBD Quality Care Evaluation Center Committee (2020) Implications of COVID-19 for patients with pre-existing digestive diseases. Lancet Gastroenterol Hepatol DOI: 10.1016/S2468-1253(20) 30076-5 [published ahead of print].

Netland J, Meyerholz DK, Moore S, Cassell M, and Perlman S (2008) Severe acute respiratory syndrome coronavirus infection causes neuronal death in the absence of encephalitis in mice transgenic for human ACE2. J Virol 82:7264-7275.

Nordman JC, Muldoon P, Clark S, Damaj MI, and Kabbani N (2014) The $\alpha 4$ nicotinic receptor promotes $\mathrm{CD} 4+\mathrm{T}$-cell proliferation and a helper T-cell immune response. Mol Pharmacol 85:50-61.

Oakes JM, Fuchs RM, Gardner JD, Lazartigues E, and Yue X (2018) Nicotine and the renin-angiotensin system. Am J Physiol Regul Integr Comp Physiol 315:R895-R906

Olds JL and Kabbani N (2020) Is nicotine exposure linked to cardiopulmonary vulnerability to COVID-19 in the general population? FEBS $J$ DOI: 10.1111/febs.15303 [published ahead of print].

Plummer HK III, Dhar M, and Schuller HM (2005) Expression of the $\alpha 7$ nicotinic acetylcholine receptor in human lung cells. Respir Res 6:29.

Qi F, Qian S, Zhang S, and Zhang Z (2020) Single cell RNA sequencing of 13 human tissues identify cell types and receptors of human coronaviruses. Biochem Biophys Res Commun DOI: 10.1101/2020.02.16.951913 [published ahead of print].

Razani-Boroujerdi S, Singh SP, Knall C, Hahn FF, Peña-Philippides JC, Kalra R, Langley RJ, and Sopori ML (2004) Chronic nicotine inhibits inflammation and promotes influenza infection. Cell Immunol 230:1-9.

Thorgeirsson TE, Geller F, Sulem P, Rafnar T, Wiste A, Magnusson KP, Manolescu A, Thorleifsson G, Stefansson H, Ingason A, et al. (2008) A variant associated with nicotine dependence, lung cancer and peripheral arterial disease. Nature 452:638-642.

Tolu S, Eddine R, Marti F, David V, Graupner M, Pons S, Baudonnat M, Husson M, Besson M, Reperant C, et al. (2013) Co-activation of VTA DA and GABA neurons mediates nicotine reinforcement. Mol Psychiatry 18:382-393.

Virdis A, Giannarelli C, Neves MF, Taddei S, and Ghiadoni L (2010) Cigarette smoking and hypertension. Curr Pharm Des 16:2518-2525.

Zhang QL, Ding YQ, Hou JL, He L, Huang ZX, Wang HJ, Cai JJ, Zhang JH, Zhang WL, Geng J, et al. (2003) [Detection of severe acute respiratory syndrome (SARS)associated coronavirus RNA in autopsy tissues with in situ hybridization]. Di Yi Jun Yi Da Xue Xue Bao 23:1125-1127.

Address correspondence to: N. Kabbani, George Mason University, 4400 University Dr., Fairfax, VA 22030. E-mail: nkabbani@gmu.edu 